\title{
Genetic Studies on Reproduction Performance of Raighar Goat in its Native Tract
}

\author{
Dash SK ${ }^{* 1}$, Sethi BP ${ }^{2}$ \\ ${ }_{1 *}$ Professor, Department of Animal Breeding and Genetics, Orissa University of Agriculture \& Technology \\ ${ }^{2}$ Former Commissioner cum Secretary, F\&ARD, Government of Odisha, Bhubaneswar, Odisha, India
}

*Correspondence to: Dash SK, Professor, Department of Animal Breeding and Genetics, Orissa University of Agriculture \& Technology, E-mail: susantdash46@gmail.com

Received: August 16, 2017; Accepted: August 24, 2017; Published: August 25, 2017;

\section{Introduction}

There are around 65 lakh goats comprising of $32 \%$ of total livestock in Odisha (19 ${ }^{\text {th }}$ livestock census, India, 2012) [1]. Goats in Odisha are meat type and are famous for their excellent meat and skin quality with high frequency of multiple births and less kidding interval (Dash, et al.,) [2]. Raighar goat is a lesser known meat type breed found in Nabarangapur district and part of Kalahandi and Nuapada district of Odisha along with a part of Chhatisgarh in India, adjacent to Nabarangapur district and mostly reared by Bhatra and Gond tribals along with Gouda community. Knowledge on reproductive potential is the most important thing for developing strategy towards genetic improvement in meat type animals like goat. Evaluation of economic reproduction traits would help to know the extent of genetic diversity present, which may be explored for future use in breeding plans. Study of the reproduction traits of these populations in detail with regard to their inheritance and relationship with other economical traits would be very beneficial for devising improvement programmes. The findings on the inheritance and association among the important reproduction traits need to be incorporated in selection indices specific to the breed or type for improvement of the desired traits.

Age and weight at sexual maturity and at first kidding along with kidding interval are the most important economic factors, which influence the growth, production and reproduction pattern of any goat type. Consideration of many economic traits to improve at a particular time is the target by all the stakeholders. Hence, genetic and phenotypic association among such traits of importance needs to be kept in mind before designing the breeding plan.

Very limited published information on heritability estimates of some reproductive traits and degree of association among those in indigenous goats of Odisha (Patro et al., Bariha et al., Rao et al., and Dash et al.,) [2-5] have been accomplished.

Keeping in view the above facts, the present study was taken up on Raighar goat to assess the heritability of reproduction parameters and genetic association among those traits in its native tract.

\section{Materials and methods}

The present study was conducted in Nabarangapur district and part of Kalahandi and Nuapada district of Odisha situated between $19^{\circ}$ $10^{\prime} \mathrm{N}$ to $20^{\circ} 16^{\prime} \mathrm{N}$ latitude and between $81^{\circ} 57^{\prime} \mathrm{E}$ to $82^{\circ} 45^{\prime} \mathrm{E}$ longitude in India. The climate ranges from hot and humid to hot and moist-sub humid. The average maximum and minimum temperatures are $42.9^{\circ}$ $\mathrm{C}$ and $11.5^{\circ} \mathrm{C}$ observed in the month of May and January, respectively. The average relative humidity ranges between 39.6 and 89.4 per cent over the months during the year. The average annual rainfall is around $1550 \mathrm{~mm}$.

Indigenous goats in the present study were reared only for meat purpose. Data on the reproductive parameters of 746 does, sired by 32 bucks, born during the period of 2 years (2013 to 2015) in 32 villages of three districts viz. Nabarangapur Kalahandi and Nuapada of Odisha were included in the present study. Kids were naturally weaned at 90 days of age. Goats were maintained exclusively under extensive system of management; mostly were allowed to graze for the entire day (around 8 hours). Dams were never milked and kids were allowed to suckle fully throughout the lactation length of around 90 days.

Data on age at sexual maturity, weight at sexual maturity, age at first kidding, weight at first kidding and kidding interval were collected directly from farmers' flocks and further grouped according to season of birth, flock size, parity and type of birth. The entire year was divided to three seasons as $S_{1}$ for summer (March to June), $S_{2}$ for rainy (July to October) and $S_{3}$ for winter (November to February). Flock size was taken as $\mathrm{F}_{1}$ for small flock ( $<10$ heads), $\mathrm{F}_{2}$ for medium flock ( $>10$ to $<20)$ and F3 for large flock ( $>20$ heads).Parity as $P_{1}$ for first parity, $\mathrm{P}_{2}$ for second parity and $\mathrm{P}_{3}$ for third parity. Type of birth as $\mathrm{T}_{1}$ for single birth, $\mathrm{T}_{2}$ for twin birth and $\mathrm{T}_{3}$ for triple birth.

The heritability of economic reproduction parameters was estimated by half sib correlation method, which is based on phenotypic resemblance between relatives as compared to unrelated individuals. The recorded data were analysed for the estimation of variation between and within sire groups and various components of variance were worked out (Kempthorne) [6]. As there were unequal numbers of off springs in individual sire groups, the average number of progeny per sire (K) was worked out by formula:

$K=\frac{1}{S-1} \times \frac{\left(N-\sum n_{i}^{2}\right)}{N}$

Where,

$\mathrm{S}=$ Number of sires

$\mathrm{N}=$ Total number of progenies used in the study 
$\Sigma=$ Sum of

$\mathrm{n}_{\mathrm{i}}=$ Number of observations on the ith sire.

The heritability was estimated by multiplying intraclass correlation (t) with the factor 4.

$t=\frac{\sigma^{2}}{\sigma^{2} w+\sigma^{2} s}$ and $h^{2}=4 t$

where,

$\mathrm{t}=$ intraclass correlation

$\mathrm{h}^{2}=$ heritability $\sigma^{2} s=$ genetic variation

$\sigma^{2} \mathrm{~W}=$ environmental variation

The data were subjected to least squares analysis using model Least-Squares and Maximum Likelihood Program (Harvey) [7] for estimation of means along with standard errors, analysis of variance, heritability and degree of association among reproductive parameters.

\section{Results and discussion}

Reproductive performance as age and weight at sexual maturity and at first kidding along with kidding interval influenced by season, flock size, parity and type of birth is presented in Table 1 .

Table 1. Least squares means along with standard errors for reproduction traits.

\begin{tabular}{|c|c|c|c|c|c|}
\hline Particulars & $\begin{array}{l}\text { Age at sexual maturity } \\
\text { (Day) }\end{array}$ & $\begin{array}{l}\text { Weight at sexual maturity } \\
\qquad(\mathrm{Kg})\end{array}$ & $\begin{array}{l}\text { Age at first kidding } \\
\text { (Day) }\end{array}$ & $\begin{array}{l}\text { Weight at first kidding } \\
(\mathbf{K g})\end{array}$ & $\begin{array}{c}\text { Kidding interval } \\
\text { (Day) }\end{array}$ \\
\hline Overall & $286.13 \pm 1.02(746)$ & $13.92 \pm 0.16(746)$ & $453.85 \pm 1.14(720)$ & $21.07 \pm 0.26(720)$ & $226.42 \pm 2.56(712)$ \\
\hline$S_{1}$ & $\begin{array}{c}285.49 \pm 1.68 \\
(198)\end{array}$ & $\begin{array}{c}13.84 \pm 0.36 \\
(198)\end{array}$ & $\begin{array}{c}451.03 \pm 1.74 \\
(192)\end{array}$ & $20.88 \pm 0.42(192)$ & $224.84 \pm 3.11(189)$ \\
\hline $\mathrm{S}_{2}$ & $\begin{array}{c}283.92 \pm 1.51 \\
(252)\end{array}$ & $\begin{array}{c}13.72 \pm 0.29 \\
(252)\end{array}$ & $\begin{array}{c}454.39 \pm 1.66 \\
(240)\end{array}$ & $\begin{array}{c}21.11 \pm 0.37 \\
\quad(240)\end{array}$ & $227.56 \pm 2.96(238)$ \\
\hline $\mathrm{S}_{3}$ & $\begin{array}{c}288.44 \pm 1.40 \\
(296)\end{array}$ & $\begin{array}{c}14.14 \pm 0.25 \\
(296)\end{array}$ & $\begin{array}{c}455.28 \pm 1.48 \\
(288)\end{array}$ & $\begin{array}{c}21.16 \pm 0.31 \\
(288)\end{array}$ & $226.52 \pm 2.88(285)$ \\
\hline$F_{1}$ & $\begin{array}{c}288.25^{\mathrm{a}} \pm 1.26 \\
(456)\end{array}$ & $\begin{array}{c}14.08^{\mathrm{a}} \pm 0.21 \\
(456)\end{array}$ & $\begin{array}{c}458.41^{\mathrm{a}} \pm 1.33 \\
(438)\end{array}$ & $\begin{array}{c}21.24^{\mathrm{a}} \pm 0.29 \\
(438)\end{array}$ & $228.17^{\mathrm{a}} \pm 2.75(432)$ \\
\hline$F_{2}$ & $\begin{array}{c}285.19^{\mathrm{a}} \pm 1.68 \\
(209)\end{array}$ & $\begin{array}{c}13.72^{\mathrm{b}} \pm 0.31 \\
(209)\end{array}$ & $\begin{array}{c}449.82^{b} \pm 1.69 \\
(204)\end{array}$ & $\begin{array}{c}20.87^{\mathrm{b}} \pm 0.39 \\
(204)\end{array}$ & $\begin{array}{c}225.36^{\mathrm{a}} \pm 2.98 \\
(203)\end{array}$ \\
\hline $\mathbf{F}_{3}$ & $\begin{array}{c}276.64^{\mathrm{b}} \pm 1.93 \\
(81)\end{array}$ & $\begin{array}{c}13.53^{\mathrm{c}} \pm 0.46 \\
\quad(81)\end{array}$ & $\begin{array}{c}438.78^{\mathrm{c}} \pm 1.97 \\
(78)\end{array}$ & $\begin{array}{c}20.64^{\mathrm{c}} \pm 0.46 \\
(78)\end{array}$ & $219.40^{b} \pm 3.31(77)$ \\
\hline$P_{1}$ & $287.28 \pm 1.42(394)$ & $\begin{array}{c}14.01 \pm 0.20 \\
(394)\end{array}$ & $\begin{array}{c}455.07 \pm 1.43 \\
(378)\end{array}$ & $\begin{array}{c}21.10 \pm 0.30 \\
\quad(378)\end{array}$ & $\begin{array}{c}226.68 \pm 2.92 \\
(374)\end{array}$ \\
\hline $\mathbf{P}_{2}$ & $285.34 \pm 1.53(228)$ & $\begin{array}{c}13.84 \pm 0.23 \\
(228)\end{array}$ & $\begin{array}{c}453.14 \pm 1.54 \\
(221)\end{array}$ & $\begin{array}{c}21.05 \pm 0.34 \\
\quad(221)\end{array}$ & $\begin{array}{c}225.49 \pm 3.23 \\
(218)\end{array}$ \\
\hline $\mathbf{P}_{3}$ & $283.94 \pm 1.71(124)$ & $\begin{array}{c}13.78 \pm 0.28 \\
(124)\end{array}$ & $\begin{array}{c}451.36 \pm 1.69 \\
(121)\end{array}$ & $\begin{array}{c}21.01 \pm 0.41 \\
\quad(121)\end{array}$ & $\begin{array}{c}227.29 \pm 3.48 \\
(120)\end{array}$ \\
\hline $\mathbf{T}_{1}$ & $286.74 \pm 1.34(493)$ & $\begin{array}{c}13.96 \pm 0.18 \\
(493)\end{array}$ & $\begin{array}{c}454.43 \pm 1.24 \\
(477)\end{array}$ & $\begin{array}{c}21.09 \pm 0.28 \\
(477)\end{array}$ & $\begin{array}{c}226.93 \pm 2.85 \\
(472)\end{array}$ \\
\hline$T_{2}$ & $285.01 \pm 1.55(226)$ & $\begin{array}{c}13.85 \pm 0.22 \\
(226)\end{array}$ & $\begin{array}{c}452.77 \pm 1.48 \\
(218)\end{array}$ & $\begin{array}{c}21.03 \pm 0.33 \\
(218)\end{array}$ & $\begin{array}{c}225.19 \pm 3.16 \\
(215)\end{array}$ \\
\hline $\mathbf{T}_{3}$ & $\begin{array}{c}284.37 \pm 1.94 \\
(27)\end{array}$ & $\begin{array}{c}13.78 \pm 0.36 \\
(27)\end{array}$ & $\begin{array}{c}452.20 \pm 1.81 \\
(25)\end{array}$ & $\begin{array}{c}20.98 \pm 0.48 \\
(25)\end{array}$ & $\begin{array}{c}227.37 \pm 4.12 \\
(25)\end{array}$ \\
\hline
\end{tabular}

*Figures in parenthesis indicate number of observations.

Different superscripts along the column (for a factor) indicate significantly $(\mathrm{P}<0.05)$ different values 
Age at sexual maturity: Overall age at sexual maturity was $286.13 \pm 1.02$ days, which corroborates with the report of Fahim et al. [8] for Rohilkhand goats in UP and Kharkar et al. [9] for Berari goats of Maharashtra. However, comparatively higher estimate was reported by Rao et al. [5] for Ganjam goats. Lower estimate was reported by Bariha et al. [4] and Mohanty et al. [2] for indigenous goats in Odisha.

Weight at sexual maturity: Average weight at sexual maturity in the present study was $13.92 \pm 0.16 \mathrm{~kg}$. Lower estimate was reported by Bariha et al. [4] and Paul et al. [10]. However, higher estimate was reported by Rao et al. [5] in Ganjam goats and Yadav and Khada (2009) [11] in non-descript goats of Rajasthan.

Age at first kidding: Overall age at first kidding was found to be $453.85 \pm 1.14$ days in the present study. The present finding is in agreement with the report of Kharkar et al. [9] However; higher estimate was reported by, Fahim et al. [8], Patel and Pandey [12] in Mehsana goats and Kumar et al. [13] in Sirohi goats. Lower values compared to the present finding was reported by Bariha et al. [4] and Faruque et al. [14] in Black Bengal goats.

Weight at first kidding: The average weight at first kidding was found to be $21.07 \pm 0.26 \mathrm{~kg}$ in the present study. The present finding is in close agreement with the report of Fahim et al. [8] Lower estimates were observed by Bariha et al. [4] and Haque et al. [19]. However, higher values were reported by Rao et al. [5] and Patel and Pandey [12] in Ganjam and Mehsana goats, respectively.

Kidding interval: The present study revealed that the kidding interval in Raighar goats was $226.42 \pm 2.56$ days. The present finding corroborates with the earlier report of Das et al. [15] in Bengal goats of West Bengal. But, higher estimates were reported by Haque et al. [16] and Singh et al. [17].

Season of birth, parity and type of birth had no significant effect on any of the reproduction traits in the present study with Raighar goats. Similar finding was observed for season of birth by Paul et al. [10] for weight and age at sexual maturity in Black Bengal goats. However, the flock size showed significant effect on all the reproductive parameters. Large flocks were found to be significantly better than medium and smaller flocks in all the parameters but medium flocks were significantly better than smaller flocks only in weight at sexual maturity, age at first kidding and weight at first kidding. This may be due to the fact that, the small flocks with less than 10 heads usually do not have a breeding buck to move in the flock. In contrary the larger flocks often own a buck, hence, the female goat in estrus gets successful service at grazing, which the female in smaller flock usually miss, resulting in delayed days open [Figures 1 to 3].

The heritability estimates of all the reproductive parameters in the present study were found to be moderate ranging from $0.192 \pm 0.081$ to $0.334 \pm 0.211$, indicating existence of substantial additive genetic variance in the population and can be utilized for improvement of the sought traits (Table 2). The low heritability estimate observed for age at sexual maturity may be explained by the differential nutritional level of the does, resulting in a large environmental variation. The heritability estimate of age at first kidding was $0.276 \pm 0.119$. This result is in close agreement with the findings of Haque et al. (2013) in
Black Bengal goats, Kebede et al. [18] in indigenous Arsi-Bale goats of Ethiopia, Bariha et al. (2008) in indigenous goats of Keonjhar and Rao et al. (2002) in Ganjam goats. The heritability estimate of kidding interval in the present study was $0.256 \pm 0.176$. Lower estimate of 0.06 and $0.14 \pm 0.96$ was reported by Kebede et al. (2012) in their study with indigenous Arsi-Bale goats and Bariha et al. [4] in indigenous goats of Keonjhar district in Odisha, respectively.
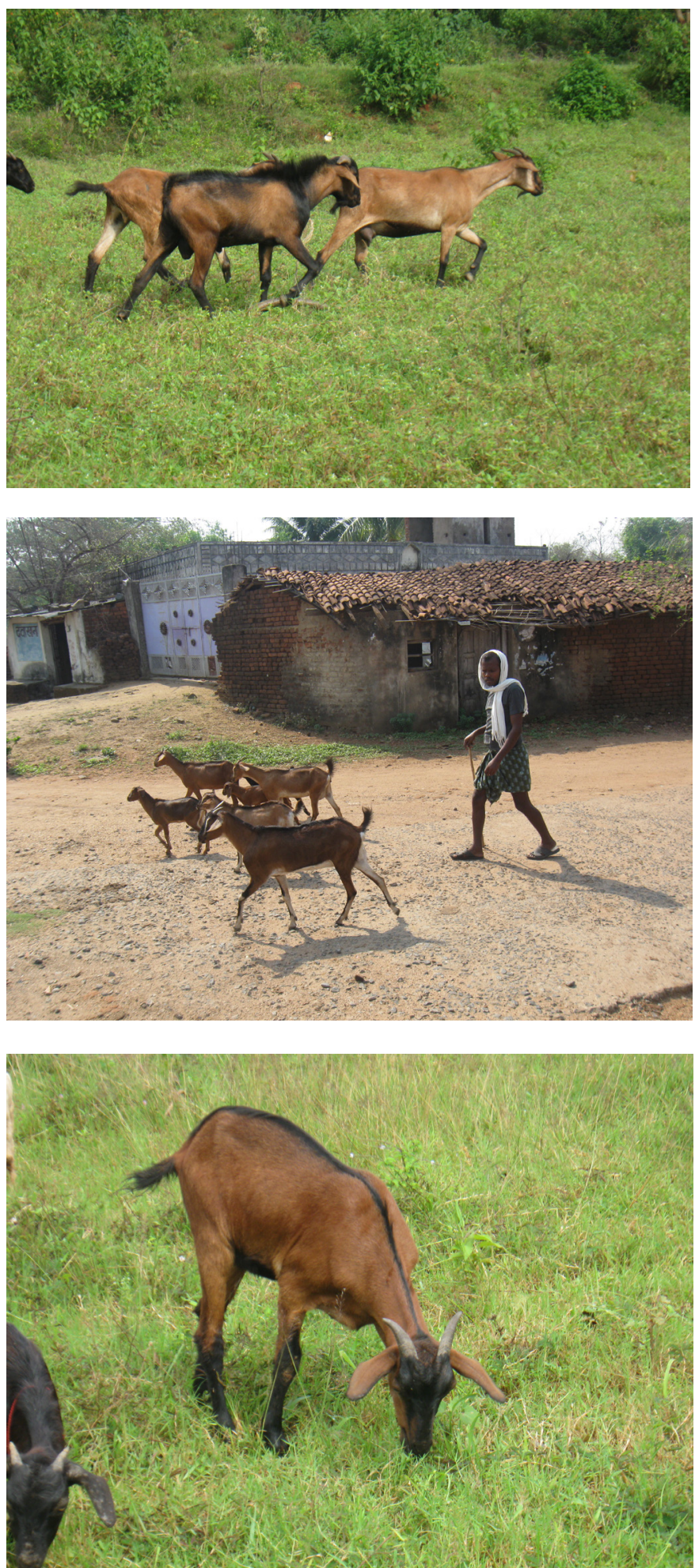
Table 2. Heritability, genetic and phenotypic correlations among reproductive traits.

\begin{tabular}{|c|c|c|c|c|}
\hline Trait & Age at sexual maturity & Weight at sexual maturity & Age at first kidding & Weight at first kidding \\
\hline Age at sexual maturity & $\mathbf{0 . 1 9 2} \pm \mathbf{0 . 0 8 1}$ & $0.687 \pm 0.156$ & $0.557 \pm 0.214$ & $0.189 \pm 0.172$ \\
\hline Weight at sexual maturity & $0.395 \pm 0.122$ & $\mathbf{0 . 3 3 4} \pm \mathbf{0 . 2 1 1}$ & $0.557 \pm 0.181$ & $0.094 \pm 0.131$ \\
\hline Age at first kidding & $0.484 \pm 0.212$ & $0.297 \pm 0.109$ & $\mathbf{0 . 2 7 6 \pm 0 . 1 1 9}$ & $0.147 \pm 0.136$ \\
\hline Weight at first kidding & $0.263 \pm 0.211$ & $0.397 \pm 0.213$ & $0.447 \pm 0.116$ & $0.214 \pm 0.118$ \\
\hline Kidding interval & $0.224 \pm 0.209$ & $0.207 \pm 0.156$ & $0.187 \pm 0.065$ & $\mathbf{0 . 3 3 1} \pm \mathbf{0 . 0 9 8}$ \\
\hline
\end{tabular}

*Values of diagonal are heritability estimates, above diagonal are genetic correlations and below diagonal are phenotypic correlations.

It was observed that the genetic correlations between age at sexual maturity with weight at sexual maturity and with age at first kidding were $0.687 \pm 0.156$ and $0.557 \pm 0.214$, respectively. The genetic correlations of kidding interval with all other reproductive traits were found to be very low. The phenotypic correlations of age at sexual maturity with weight at sexual maturity, age at first kidding and weight at first kidding were found to be medium and positive.

\section{Conclusion}

As flocks with more than 10 heads were better in reproduction, recommendation may be made to rear at least 10 females and a buck to obtain optimum efficiency in reproduction. The heritability estimates, being moderate, indicated that selection for reproduction performance may be done on the basis of individual selection with proper nutrition and other managemental care. A positive response could be expected in almost all traits owing to the moderate to high and positive genetic correlations among the economic reproductive traits which gives a scope for simultaneous selection of more than one trait at a time.

\section{Acknowledgements}

The authors are thankful to Chief District Veterinary Officers of Nabarangapur, Nuapada and Kalahandi district in Odisha for their cooperation in conducting this research work.

\section{References}

1. Government of India, Livestock Census (2012) Available on www.http: //dahd.nic. in/LStock.htm.

2. Dash SK, Mohanty GP, Kanungo S, Palai TK and Sahu S (2011). Factors influencing body weight of indigenous goats of Mayurbhanj district in Orissa. J Res 1: 196-198.

3. Patro BN, Nayak S, Rao PK and Panda P. (2007) Genetic studies of Ghumusar goats of Orissa. Indian J Anim Breed. \& Genetics 27: 12-16.

4. Bariah SP, Rao PK, Patro BN, Dash SK and Panda P (2008) Genetic analysis of indigenous goats of Keonjhar district of Orissa. Indian Vet $J$ 85: 843-845.

5. Rao PK, Dash SK, Singh MK, Rai B and Singh NP (2009) Ganjam goat of Orissa and its management practices. Indian J of Small Ruminants 1: 44-50.

6. Kempthorne O (1957) An introduction to genetic statistics. John Wiley and Sons Inc. New York. USA.

7. Harvey WR (1990) User's Guide for LSMLMW, PC-2 Version, Mixed Model Least Squares and Maximum Likelihood Computer Program, Mimeograph, Columbus, Ohio, USA.

8. Fahim A, Singh M, Patel BHM, Mondal SK and Dutt T. (2013). Reproductive performance and milk yield of Rohilkhand goat. The Indian J Small Ruminants 1: $32-35$

9. Kharkar K, Kuralkar SV and Kuralkar P (2014) Growth, production and reproduction performance of Berari goats in their native tract. Indian Journal of Small Ruminants 1: 12-15.
10. Paul RC, Rahman ANMI, Debnath S, Khandoker MAMY (2014) Evaluation of productive and reproductive performance of Black Bengal goat. Bang. J Anim Sci 2: $104-111$.

11. Yadav CM and Khada BS (2009) Management practices and performance of goats in tribal belt of Dungarpur district in Rajasthan. Indian Journal of Small Ruminants 1: 131-133.

12. Patel AC and Pandey DP (2013) Growth, Production and Reproduction Performance of Mehsana Goat. J Livestock Sci 4: 17-21.

13. Kumar MU, Nagda RK and Sharma SK (2012) Reproductive status of Sirohi goats under field conditions. Indian Journal of Small Ruminants 1: 143-144.

14. Faruque S, Chowdhury SA, Siddiquee NU and Afroz MA (2010). Performance and genetic parameters of economically important traits of Black Bengal goat. Journal of Bangladesh Agricultural University. 8: 67-78.

15. Dash SK, Rao PK and Patro BN (2010). Selection index for improvement of production performance in goats. Indian Vet $J$ 87: 359-362.

16. Haque MN, Husain SS, Khandoker MAMY, Mia MM and Apu AS (2013) Selection of Black Bengal Buck Based on Some Reproductive Performance of Their Progeny at Semi-Intensive Rearing System. Journal of Agricultural Science 8: 142-152.

17. Singh KP, Dixit SP, Singh PK, Pandey DP and Ahlawat SPS (2009) A note on growth and reproduction traits of Mehsana goats under farmer's flocks. Indian J of Small Ruminants 2: 271-273.

18. Kebede T, Haile A, Hailu D and Alemu T (2012) Genetic and phenotypic parameter estimates for reproduction traits in indigenous Arsi-Bale goats. Trop Anim Health Prod 44: 1007-1015.

\section{Citation:}

Dash SK, Sethi BP (2017) Genetic Studies on Reproduction Performance of Raighar Goat in its Native Tract. Integr J Vet Biosci Volume 1(1): 1-4 